\title{
ANALISIS DAMPAK PERCEIVED ORGANIZATIONAL SUPPORT TERHADAP TINGKAT TURNOVER INTENTION
}

\author{
Chintya Chandra \\ Alumni Fakultas Ekonomi dan Bisnis, Universitas Ma Chung
}

\begin{abstract}
ABSTRAKSI
Tujuan penulis menulis jurnal ini adalah untuk mengetahui pengaruh Perceived Organizational Support terhadap tingkat Turnover Intention. Didorong dengan permasalahan Turnover di Indonesia yang saat ini belum dapat terselesaikan, dan masih menjadi suatu momok yang berbahaya bagi setiap perusahaan. Permasalahan ini dapat terjadi akibat tingkat Perceived Organizational Support yang rendah dalam suatu perusahaan. Dengan tingginya tingkat kepedulian karyawan terhadap hal ini maka kemungkinan besar tingkat turnover intention di Indonesia lebih menurun. Dengan tingkat turnover yang menurun maka produktivitas karyawan untuk meningkatkan value perusahaan akan meningkat. Dalam menghadapi MEA yang sudah mulai dibuka dan perusahaan-perusahaan asing berpeluang besar membuka usaha di Indonesia. Untuk mempersempit pergerakan perusahaan asing maka perusahaan lokal harus semakin kuat dan terus berkembang. Oleh karena itu diperlukan Perceived Organizational Support yang tinggi agar karyawan merasa lebih nyaman dalam lingkungan pekerjaannya dan tingkat Turnover Intention karyawan di Indonesia dapat mengalami penurunan. Sehingga dengan tingkat pengangguran yang rendah maka karyawan di Indonesia tidak banyak yang menganggur dan perusahaan local semakin kuat.
\end{abstract}

Kata Kunci : MEA, Perceived Organizational Support, turnover intention

\section{ABSTRACT}

The author wrote this journal purpose is to determine the effect on turnover intention perceived organizational support driven by turnover problems in Indonesia which has yet to be resolved, and still be a scourge that is dangerous for any company. This issue can occur due to the level of Perceived Organizational Support that low in an enterprise. With the high level of awarenessof employees to this turnover rate then most likely intention in Indonesia Decrease more. With a declining turnover rate then the employee productivity to increase the company's value will increase. In the face of an MEA already opened and foreign companies had a great opening business in Indonesia. To narrow down the movement of the foreign company then local companies must increasingly strong and growing. Therefore it is necessary that high post so that employees feel more comfortable in the work environment and the level of Tunover Intention employees in Indonesia can be decreased. So with a low unemployment rate, the employee in Indonesia are not many who are unemployed and local companies getting stronger.

Keyword: AEC, Perceived Organizational Support, turnover intention

\section{PENDAHULUAN}

Dalam ilmu Manajemen Sumber Daya Manusia terdapat sebuah istilah dalam aspek perilaku organisasi yaitu Perceived Organization Support. Perceived Organization Support didefinisikan sebagai keyakinan umum karyawan tentang sejauh mana organisasi menghargai kontribusi mereka dan peduli tentang kesejahteraan mereka (Eisenberger et al.,1986). Yang saat ini perusahaan-perusahaan sangat memerlukan aspek Perceived Organization Support dalam menurunkan tingkat Turnover Intention karyawan yang saat ini masih mengecam negara Indonesia. Turnover Intention adalah kecenderungan sikap atau tingkat dimana seorang karyawan memiliki kemungkinan untuk meninggalkan organisasi atau mengundurkan diri secara sukarela dari pekerjaanya Bluedorn dalam Grant et al., (2001). Dengan adanya support dari organisasi, karyawan menjadi nyaman bekerja dan kondisi kerja semakin kondusif serta keadilan yang diterima oleh karyawan, maka mereka akan semakin merasa lebih dihargai.

Dalam penelitian ini penulis ingin mengetahui dampak langsung dari Perceived Organizational Support terhadap tingkat 
Turnover Intention yang selama ini menjadi masalah yang masih belum terselesaikan dan membutuhkan analisis untuk membuktikan berpengaruh atau tidaknya Perceived Organizational Support terhadap tinggi atau rendahnya tingkat Turnover Intention di Indonesia. Selain itu permasalahan ini menjadi masalah yang bertubi-tubi karena dengan tingkat turnover yang tinggi kemungkinan besar pengangguran dapat lebih bertambah banyak, semakin besar peluang pekerja asing yang memasuki dan menguasai perekonomian serta tenaga kerja di Indonesia khususnya dalam menghadapi MEA yang telah dibuka pada tahun 2016 ini.

Selain mengetahui dampaknya, penulis juga ingin memberikan sedikit informasi mengenai manfaat Perceived Organizational Support yang selama ini memang dinilai cukup diperlukan dalam sebuah karyawan untuk menciptakan kenyamanan kerja. Walaupun seorang karyawan memiliki kompensasi yang tinggi tetapi tingkat keadilan, kenyamanan dan penghargaan kerja yang rendah selalu dia peroleh maka akan menumbuhkan stress kerja yang berkepanjangan dan membuat karyawan itu semakin tidak produktif dalam melakukan pekerjaannya. Maka dari itu manfaat dari adanya penelitian ini mahasiswa menjadi mengerti hubungan serta pengaruh nyata dari Perceived Organizational Support yang harus diciptakan dalam dunia kerja sehingga dapat menjadi bekal saat memasuki dunia kerja nantinya. Serta untuk para karyawan dengan adanya penelitian ini semakin belajar untuk meningkatkan Perceived Organizational Support dalam oerganisasi kerja mereka agar tercipta lingkungan kerja yang nyaman dan kondusif sehingga pekerjaan pun dapat lebih mudah dan lebih cepat terselesaikan. Karena tidak dapat dipungkiri bahwa di semua dunia kerja bahkan semua perusahaan pasti memiliki masalah ini dan mungkin mereka tidak menghiraukan dan membiarkannya. Sebab masalah sekecil apapun dalam dunia kerja harus segera diselesaikan karena masalah kecil lama kelamaan apabila dipendam pada akhirnya dapat menjadi masalah besar yang sukar untuk dipecahkan.

Dapat disimpulkan oleh penulis bahwa Perceived Organizational Support adalah seberapa besar dukungan organisasi yang dirasakan karyawan terhadap kontribusi mereka dan kepedulian organisasi terhadap kesejahteraan mereka yang akan berdampak kepada dukungan karyawan terhadap organisasi. Perceived Organizational Support dapat meningkatkan kepercayaan karyawan terhadap organisasi, meningkatkan semangat kerja karyawan, karyawan lebih berkomitmen kepada organisasi dan hasil pekerjaan individual dan organisasi akan meningkat.

\section{Perceived Organization Support}

Perceived Organization Support merupakan sebuah aspek penting yang harus dimiliki oleh sebuah organisasi karena dengan aspek tersebut maka sebuah organisasi dapat berjalan dengan produktif. Dengan hal ini terdapat dua anteseden dari perceived organizational support yang dirasakan karyawan yaitu kepercayaan karyawan dalam suatu organisasi yang akan mempengaruhi persepsi mereka terhadap kualitas hubungan pertukaran dengan organisasi yaitu perceived organizational support.

Kepercayaan karyawan dalam suatu organisasi yang akan mempengaruhi persepsi mereka terhadap kualitas hubungan pertukaran dengan organisasi yaitu perceived organizational support. Kepercayaan didefinisikan sebagai asumsi bahwa orang lain dapat diandalkan untuk melakukan apa yang mereka katakan. Ketika pemimpin telah mempercayai hal itu maka karyawan tentu akan merasakan hal yang sama pula terhadap organisasinya. Secara tidak langsung akan berdampak pada meningkatnya komitmen organisasi karyawan

Akses terhadap informasi, yaitu ketika seseorang pemimpin bersedia untuk berbagi informasi baik atau buruk, mereka akan memperoleh kepercayaan dari karyawan. Karyawan akan merasa bahwa mereka memiliki perhatian dari pemimpin mereka dan mereka dipercaya oleh pemimpin mereka. Melalui berbagi informasi, perbaikan secara terus-menerus dapat Kesempatan untuk belajar dan mengembangkan, yaitu melalui kesempatan pelatihan dan pengembangan yang profesional, tentu tidak hanya meningkatkan kinerja karyawan namun juga kepercayaan diri karyawan. Apabila kepercayaan diri tersebut meningkat, tentu tidak hanya kinerja, kepuasan dan komitmen yang meningkat namun juga persepsi karyawan terhadap organisasi dimana karyawan merasa telah dihargai dan diberikan 
kesempatan untuk berkembang oleh organisasinya.

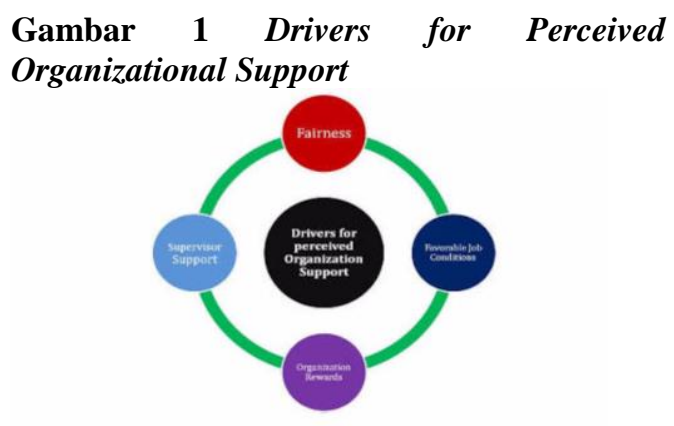

Sumber : www.slideshare.com

Dari aspek-aspek diatas merupakan siklus aspek dari Perceived Organizational Support dan terus berada dalam lingkaran tersebut apabila tidak segera diselesaikan dengan pemberian keadilan dan kelayakan kerja pada karyawan yang memang semua pemecahan masalah memiliki konsekuensi yang berbeda-beda setiap perusahaan. Tetapi organisasi tersebut harus berani mengambil sebuah upaya yang tegas dan terus bekerja sama dalam kondisi apapun.

\section{Hubungan Karyawan dengan Perceived Organizational Support}

Diindikasikan bahwa terdapat 3 kategori utama dari perlakuan yang dipersepsikan oleh karyawan memiliki hubungan dengan perceived organizational support. Ketiga kategori utama ini adalah keadilan, dukungan supervisor, Penghargaan Organisasi dan Kondisi Pekerjaan. Karyawan sangat memerlukan keadilan dalam perilaku berorganisasi antar rekan kerja maupun antara atasan dan bawahan. Keadilan prosedural menyangkut cara yang digunakan untuk menentukan bagaimana mendistribusikan sumber daya di antara karyawan. (Greenberg, dalam Rhoades \& Eisenberger 2002). Shore dan Shore (dalam Rhoades \& Eisenberger, 2002) menyatakan bahwa banyaknya kasus yang berhubungan dengan keadilan dalam distribusi sumber daya memiliki efek kumulatif yang kuat pada perceived organizational support dimana hal ini menunjukkan bahwa organisasi memiliki kepedulian terhadap kesejahteraan karyawan..

Karyawan mengembangkan pandangan umum tentang sejauh mana atasan menilai kontribusi mereka dan peduli terhadap kesejahteraan mereka (Kottke \& Sharafinski, dalam Rhoades \& Eisenberger, 2002). Karena atasan bertindak sebagai agen dari organisasi yang memiliki tanggung jawab untuk mengarahkan dan mengevaluasi kinerja bawahan, karyawan pun melihat orientasi atasan mereka sebagai indikasi adanya dukungan organisasi (Levinson dkk., dalam Rhoades \& Eisenberger, 2002).

Bentuk dari penghargaan organisasi dan kondisi pekerjaan ini adalah pelatihan yang dilihat sebagai investasi pada karyawan yang nantinya akan perceived organizational support. Gaji, pengakuan dan promosi yang sesuai dengan teori dukungan organisasi, kesempatan untuk mendapatkan gaji, pengakuan dan promosi akan meningkatkan kontribusi karyawan dan akan meningkatkan perceived organizational support. Keamanan dalam bekerja juga sangat diperlukan oleh seorang karyawan yaitu menjadi jaminan bahwa organisasi ingin memperhatikan keangotaan di masa depan dengan memberikan indikasi yang kuat terhadap perceived organizational support.

\section{Turnover Intention}

Turnover intentions (keinginan berpindah) mencerminkan keinginan individu untuk meninggalkan organisasi dan mencari alternatif pekerjaan (Suwandi dan Indriantoro 1999). Robbins (1996), menjelaskan bahwa turnover dapat terjadi secara sukarela (voluntary turnover) maupun secara tidak sukarela (involuntary turnover). Voluntary turnover atau quit merupakan keputusan karyawan untuk meninggalkan organisasi secara sukarela yang disebabkan oleh faktor seberapa menarik pekerjaan yang ada saat ini, dan tersedianya alternatif pekerjaan lain.

\section{Gambar 2. Tingkat Turnover di Indonesia}

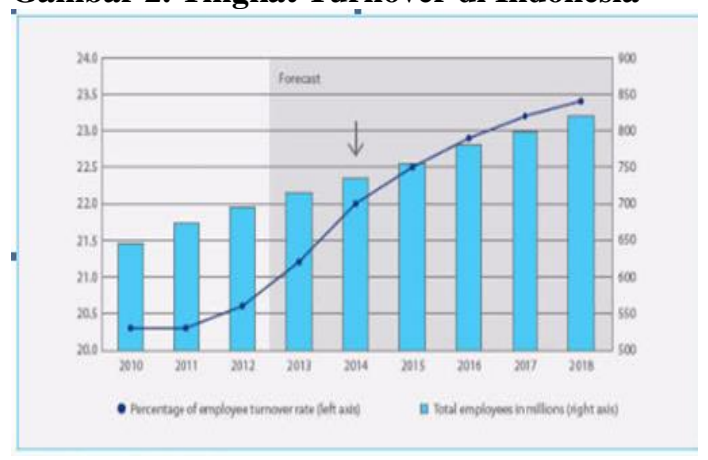


Sumber : Global turnover and number of employees Hay Group analysis

Dapat dilihat pada grafik diatas, sampai saat ini permasalahan turnover intention karyawan di Indonesia masih tinggi dan mengakibatkan pengangguran yang terus meningkat dan meresahkan negara Indonesia. Banyak akibat-akibat dari turnover intention pada karyawan salah satunya kurang nyamannya kondisi kerja dan support dari supervisor dan rekan kerja. Adapun factorfaktor turnover intention ada delapan faktor, diantaranya adalah faktor kepuasan kerja, komitmen organisasional, kepercayaan organisasional, job insecurity, konflik peran, ketidakjelasan peran, locus of control, dan perubahan organisasional. Maka dari itu untuk menurunkan tingkat turnover di Indonesia yang masih belum dapat diselesaikan maka perusahaan-perusahaan harus terus memperhatikan aspek-aspek yang dapat meningkatkan turnover pada karyawannya. Maka sebagai pemilik perusahaan atau supervisor harus memperhatikan kepuasan kerja karyawannya, komitmen dan kepercayaan dari organisasional yang disepakati bersama, dan yang terpenting memperhatiakan konflik yang terjadi serta perubahan-perubahan yang signifikan bila terjadi perubahan yang menurunkan produktivitas maka harus diperbaiki agar lebih terstruktur.

\section{Hubungan Perceived Organization Support terhadap Turnover Intention}

Pada dasarnya Perceived

organizational support yang tinggi cenderung menurunkan keinginan karyawan untuk meninggalkan organisasinya. Salah satu cara karyawan untuk membayar organisasi apabila mereka telah dihargai adalah melalui partisipasi lanjutan dimana akan mendorong timbulnya perasaan keanggotaan organisasi sebagai bagian penting dari identitas diri karyawan. Itu sebabnya karyawan merasa dihargai dan memperoleh keadilan serta merasa nyaman dengan kondisi kerjanya.

Sehingga dengan suasana kerja yang nyaman dan mendapat dukungan dari rekan kerja maka akan meningkatkan produktivitas kerja karyawan yang selanjutnya akan berdampak pada kompensasi sehingga karyawan akan lebih nyaman bekekrja dan perusahaan memiliki peluang yang rendah terhadap tingkat turnover intention karyawan. Dengan terjadinya hal tersebut tingkat pengangguran di Indonesia pun dapat berkurang karena rendahnya tingkat turnover dan dengan Perceived Organization Support yang tinggi membuat perusahaan itu terus maju sehingga karyawan merasa bangga bekerja di perusahaan tersebut.

Dampak dari Perceived Organization Support yang rendah adalah dapat meningkatkan turnover intention karyawan. Turnover Intention yang tinggi menandakan bahwa banyaknya karyawan yang mengalami PHK. Tingginya PHK akan berdampak pada pengangguran, sedangkan masalah pengangguran di Indonesia tidak selesaiselesai dan terus menumpuk. Turnover Intention yang terlalu tinggi dalam sebuah perusahaan menandakan bahwa perusahaan tersebut kurang terstruktur dan pengorganisasian dalam perusahaan tersebut rendah dan kurang produktif.

\section{Gambar 3. Hubungan POS dengan Turnover}

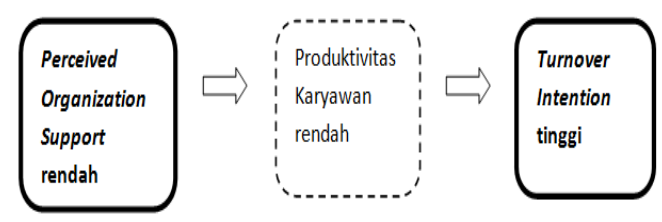

Sumber : penelitian terdahulu

Dari gambar diatas dapat menjawab permasalahan Turnover Intention di Indonesia yang menjadi masalah yang belum terselesaikan karena masih banyak warga Indonesia yang menganggur dan tidak bekerja akibat banyak hal. Salah satunya Perceived Organizational Support yang rendah yang mengakibatkan produktivitas rendah sehingga tingkat turnover tinggi. Oleh sebab itu diperlukan dorongan yang tinggi dari organisasi yaitu keadilan saat bekerja, support supervisor, penghargaan saat bekerja dan kondisi kerja yang nyaman.

\section{Kesimpulan}

Turnover Intention yang merupakan salah satu masalah yang belum terselesaikan di Indonesia seharusnya dapat diselesaikan 
dengan berbagai cara salah satunya dengan pemberlakuan Perceived Organizational Support di sebuah organisasi karena Perceived Organization Support merupakan salah satu aspek dari perilaku organisasi yang sangat penting di berlakukan dalam perusahaan.

Perceived Organization Support yang merupakan salah satu aspek dari Perilaku Organisasi ini memang sangat besar kaitannya dengan dunia kerja saat ini dan dapat berpengaruh dalam kemunculan masalah dalam pekerjaan seperti stress kerja, kinerja yang menurun, kurangnya semangat kerja, dan kurangnya kepercayaan diri karyawan terhadap apa yang ia kerjakan. Dan semua permasalahan tersebut banyak ditemui hampir di semua perusahaan baik itu perusahaan besar maupun usaha kecil.

Beberapa aspek juga wajib di implementasikan seperti keadilan, support supervisor, penghargaan kerja dan kondisi kerja yang harus diberlakukan dalam sebuah organisasi. Sehingga dapat menurunkan tingkat Turnover Intention pada karyawan dan lebih meingkatkan produktivitas kerja mereka. Lingkungan kerja sangat berdampak penting bagi produtifitas begitu juga support sesama rekan kerja dan supervisor yang mendukung menurunnya tingkat turnover intention karyawan.

Dengan masalah yang tak kunjung selesai dan aspek-aspek dalam Perceived Organizational Support itu terus menjadi permasalahan yang membuat karyawan menjadi memilih untuk keluar dan mencari pekerjaan lain yang sering disebut Turnover Intention dalam ilmu Manajemen Sumber Daya Manusia. Oleh sebab itu perlu ada solusinya yaitu meningkatkan beberapa factor seperti kepuasan kerja, komitmen organisasional, kepercayaan organisasional, job insecurity. Serta bila ada konflik dalam peran antar karyawan harus segera diselesaikan baik-baik dan tidak menunggu hingga masalah itu dipendam dan menjadi masalah besar yang sukar untuk diselesaikan.
Juga menyelesaikan permasalahan yang timbul akibat ketidakjelasan peran karyawan serta permasalahan locus of control yaitu keyakinan dalam diri seseorang sedangkan dalam organisasi terdiri dari beberapa orang yang memiliki berbagai keyakinan pemikiran dalam memecahkan masalah atau mencari ide oleh sebab itu harus menyelesaikan masalah bersama dan tidak egois satu sama lain. Dan perubahan struktur organisasional yang dapat terjadi akibat pergantian jabatan antar karyawan perusahaan yang banyak ditemukan diperusahaan manapun ataupun adanya karyawan baru ataupun supervisor yang baru.

\section{DAFTAR PUSTAKA}

1. Eisenberger, R., Cummings, J., Armeli, S., \& Lynch, P. 1997. "Perceived organizational support, discretionary treatment, and job satisfaction". Journal of Applied Psychology, 82, 812-820.

2. Eisenberger, R., Armeli, S., Rexwinkel, B., Lynch, P.D., \& Rhoades, L. 2001. "Reciprocation of perceived organizational support". Journal of Applied Psychology, 86, 42-51.

3. Eisenberger, R., Stinglhamber, F., Vandenberghe, C., Sucharski, I.L., \& Rhoades, L. 2002. "Perceived supervisor support: Contributions to perceived organizational support and employee retention". Journal of Applied Psychology, 87, 565-573.

4. Suwandi \& Indriantoro, N. (1999) Model Turnover Pasewark \& Strawser: Studi Empiris pada Lingkungan Akuntan Publik. Jurnal Riser Akuntansi Indonesia, 2. 173-195.

5. Robbins, Stephen P, 1996, Perilaku Organisasi: Konsep, Kontroversi, Aplikasi, Alih Bahasa Hadyana Pujaatmaka dan Benyamin Molan, Jilid Pertama, Penerbit Prenhallindo, Jakarta 